Short Communication

\title{
Electrochemical Sensor Based on Molecularly Imprinted Polymer for Determination of Nonylphenol
}

\author{
Benzhi Liu ${ }^{1,2, *}$, Jinlong Yan $^{2}$, Min Wang ${ }^{2}$, Xiangyang $W u^{1, *}$ \\ ${ }^{1}$ School of Environment and Safety Engineering, Jiangsu University, Zhenjiang, Jiangsu Province, \\ China, Postcode: 212013. \\ ${ }^{2}$ School of Environmental Science and Engineering, Yancheng Institute of Technology, Yancheng, \\ Jiangsu Province, China, Postcode: 224051. \\ *E-mail: benzhiliu@,163.com (B. Liu); wuxy@ujs.edu.cn (X. Wu)
}

doi: $10.20964 / 2018.12 .17$

Received: 20 July 2018 / Accepted: 13 September 2018 / Published: 5 November 2018

\begin{abstract}
Molecularly imprinted polymers were prepared on the surface of acrylamide-functionalized multiwalled carbon nanotubes by thermal polymerization, which using nonylphenol as template molecule, methacrylic acid as functional monomer and ethyleneglycol dimethacrylate as crosslinking agent. The molecularly imprinted polymers were modified on the surface of glassy carbon electrode to prepare electrochemical sensor. The proposed sensor showed a linear range of 0.1 to $30 \mu \mathrm{M}$ with a detection limit of $0.02 \mu \mathrm{M}$. The sensor exhibited good stability, selectivity and high sensitivity to nonylphenol detection. It was successfully applied to detect nonylphenol in water samples.
\end{abstract}

Keywords: Molecularly imprinted polymers, Electrochemical sensor, Nonylphenol

\section{$\underline{\text { FULL TEXT }}$}

(C) 2018 The Authors. Published by ESG (www.electrochemsci.org). This article is an open access article distributed under the terms and conditions of the Creative Commons Attribution license (http://creativecommons.org/licenses/by/4.0/). 